\title{
The relationship between social capital and self-rated health in a Japanese population: a multilevel analysis
}

\author{
Yuri Hibino · Jiro Takaki $\cdot$ Keiki Ogino • \\ Yasuhiro Kambayashi · Yoshiaki Hitomi • \\ Aki Shibata $\cdot$ Hiroyuki Nakamura
}

Received: 26 January 2011/Accepted: 11 April 2011/Published online: 26 May 2011

(C) The Japanese Society for Hygiene 2011

\begin{abstract}
Objective The aim of this study was to use a multilevel analysis to examine whether cognitive and structural dimensions of regional social capital were associated with individual health outcomes after adjusting for compositional factors.

Methods Data from the Japanese General Social Surveys project, a nationwide study with a two-stage stratified random sampling method conducted in 2000, 2001, 2002, 2005, and 2006, were aggregated and used for the multilevel analysis $(n=11,702)$. We examined whether both cognitive and structural aspects of social capital (social trust, neighborhood safety, and social participation) were associated with the self-rated health (SRH) of residents from 118 regions after adjustment for compositional factors.

Results Social trust and existing neighborhood safety were negatively associated with poor SRH, whereas the effect of social participation was not significant. Social trust was still negatively associated with poor SRH after adjusting for individual demographic factors and socioeconomic status $(p=0.001)$. In contrast, neighborhood safety and social participation did not reach significance after adjusting for compositional factors.
\end{abstract}

Y. Hibino $(\bowtie)$ · Y. Kambayashi · Y. Hitomi · A. Shibata ·

H. Nakamura

Department of Environmental and Preventive Medicine, Faculty of Medicine, Institute of Medical, Pharmaceutical and Health Sciences, Kanazawa University,

13-1 Takaramachi, Kanazawa, Ishikawa, Japan

e-mail: hibino@staff.kanazawa-u.ac.jp

J. Takaki $\cdot$ K. Ogino

Department of Public Health, Graduate School of Medicine, Dentistry and Pharmaceutical Sciences, Okayama University, Okayama, Japan
Conclusion Based on the results of this study, social trust was associated with health outcomes. Further study is needed to clarify the path linking regional trust in others to individual health outcomes in the Japanese population.

Keywords Social capital - Self-rated health .

Multilevel analysis $\cdot$ Japanese population $\cdot$ JGSS

\section{Introduction}

In the field of social epidemiology, social capital is regarded as an important determinant of a population's health [1]. In the public health field, researchers have frequently used the social capital definitions presented by the political scientist R. Putnam, who referred to "features of social organization, such as trust, norms, and networks, which can improve the efficacy of society by facilitating coordinated actions" [2]. Social capital has been measured in empirical studies in terms of cognitive dimensions, such as trust and norms of reciprocity, and structural dimensions, such as participation in voluntary or civic organizations [3]. Social capital has been conceptualized as both a collective and an individual variable separately as well as considered to be both types of variables, sometimes simultaneously, in multilevel analyses [4].

The relative-income hypothesis presumes that social capital plays an important role [5, 6]. A widely accepted theory on the pathway of the relative-income effect is that inequality disrupts community cohesion and resident's social capital and, consequently, has a negative impact on the health of a community's residents [7, 8]. Therefore, social capital might have a protective effect against deteriorating health among the population. 
The effect of social capital on health is therefore presumed to be primarily positive [9]. A number of multilevel studies have shown that a positive association exists between regional social capital and individual health outcome $[10,11]$. However, several studies have also shown that excessive cohesion may have a damaging effect on health [12].

Although a large number of studies in the field of social epidemiology have been conducted in Western countries [4, 13, 14], it remains unclear whether regional social capital has a beneficial effect on health in the Japanese population and if there are positive effects, which aspect of social capital is effective. The aim of this study was to use a multilevel analysis to examine whether cognitive and structural dimensions of regional social capital are associated with individual health outcome after adjusting for possible confounding and compositional factors.

\section{Methods}

\section{Data source}

Data from the Japanese General Social Surveys (JGSS) were used. The JGSS consist of cross-sectional social surveys that include over 200 items; they have been used to investigate the attitudes and behavior of Japanese people aged 20-89 years. In the study reported here, data from JGSS-2000, -2001, -2002, -2005, and -2006 were aggregated and analyzed based on the premise that participants did not overlap in these cross-sectional datasets. In the JGSS surveys, data were collected on each respondant using both face-to-face interviews and selfadministered surveys. Informed consent was obtained from the study participants. The sample area of the JGSS was nationwide, and the sampling method used was twostage stratified random sampling. The number of answers and the response rate were 2,893 (response rate 64.9\%) in $2000,2,790(63.1 \%)$ in $2001,2,953(62.3 \%)$ in 2002 , $2,023(50.5 \%)$ in 2005 , and $2,124(59.8 \%)$ in 2006 . The lower response rate in 2005 was assumed to be due to the issuing of a Japanese law on the protection of personal information in that year. Full details of the study are reported elsewhere (http://jgss.daishodai.ac.jp/english/ surveys/sur_top.html). The JGSS data were provided for purposes of a secondary analysis; therefore, institutional review board approval was not necessary. The privacy and anonymity of the respondents was strictly protected. All individuals for whom all relevant data were available $(n=11,702)$ were included in the study and their data analyzed.
Health outcome: self-rated health

Self-rated health (SRH) was selected as the health outcome variable because of its validity as a predictor of mortality and morbidity in longitudinal studies [15-18]. Studies conducted in the USA and internationally have demonstrated that global SRH is an independent predictor variable of overall mortality in studies using the longitudinal design [18]. SRH was assessed based on the response to the following question: "How would you rate your health condition?" using a 5-point visual analogue scale, ranging from 1 (good) to 5 (poor). Although the distribution of the health outcome variable was slightly skewed in our study, the SRH among the general population was assumed to be normally distributed, based on the lack of respondents reporting poor health.

Regional-level variables: cognitive and structural social capital

Social trust and neighborhood safety were adopted as a composite surrogate variable for cognitive social capital. The extent of trust was assessed by responses to the following single item: "Generally speaking, would you say most people can be trusted?" The possible responses were "yes," "no," and "it depends." The percentage of those answering "yes" in each community was considered to be the regional social capital.

Neighborhood safety was assessed by responses to the following item: "Is there any area (within 15-min walk) of your home where you would be afraid to walk alone at night?" The possible responses were "yes" and "no," and this was treated as a dichotomous variable.

Structural social capital was measured by a question on each individual's participation in eight kinds of social groups: "Are you a member of the following organizations: political associations, trade associations, social service groups, citizen's movement, consumer cooperative groups, religious groups, sports groups and clubs, hobby groups or clubs (chorus, photography, mountain hiking, etc.)?" Possible responses were "yes" and "no," for each group; if the respondent belonged to at least one group, he/she was regarded as participating in social activities. The structural social capital variable was thus used as a dichotomous variable.

Regional-level variables: regional unit

Japan consists of 47 prefectures, and these were used as one of the regional units in our study. Prefectures are Japanese administrative units and are demographically and economically more homogeneous than larger areas. 
However, each prefecture includes areas with cities of different sizes. At this level, regional size consisted of three categories ("one of 13 metropolitan cities," "other city," and "town or village"); responses were consolidated into two categories, which were used as a second regional unit and categorized dichotomously (13 largest cities/other city and town). We also used data from multiple surveys. Therefore, regions were divided according to 47 prefectures, two categories of regional size (13 largest cities vs. other city/town), and two categories of survey years (2000-2002/2005-2006). As a result, 118 regions were ultimately available for analysis as regional-level variables after the missing categories were deleted. Sample size within each of the 118 regions ranged from 16 to 385 .

Regional social capital for the 118 areas was measured based on aggregated individual answers. That is, we calculated the percentage of respondents who responded "yes" for each neighborhood.

\section{Compositional variables}

Gender and age were adopted as individual demographic factors, and marital status, education, employment status, and household income as socioeconomic status (SES) variables.

Age was treated as a continuous variable for the analysis of the linear association between age and health outcome. Employment status was classified into executive, regular employee, part-time worker, temporary worker, selfemployed/family worker, and unemployed. Education was classified into four categories according to duration [primary only ( $<12$ years) and $\geq 12, \geq 14, \geq 16$ years). The income measure was annual household income from 19 categories before taxes, including pensions and interest from the previous year. The median value of each category was adjusted for family size to calculate equivalent income by dividing household income by the square root of the number of family members [19]. The equivalent income was then divided into quartiles. It is known that the income level response rate in social surveys is generally low and that this might imply systematic bias. Therefore, the data for respondents who did not report their income were retained, and a "missing income" category was fitted as a dummy variable. Household income information was divided into five categories (quartiles 1-4 plus "missing").

\section{Statistical analysis}

A multilevel analysis using a random intercept model [20] was performed with data from 11,702 individuals nested within the 118 regions of Japan. Multilevel analysis has been developed to consider nested data found in many studies, such as regional effects studies. This approach allowed us to investigate how much of the area differences in health can be explained by differences in the individual characteristics of an area (compositional effect) and how much can be explained by the regional level of social capital (contextual effect). The multilevel model prevents an underestimate of the regression coefficient standard errors in a typical multivariate analysis. The deviation information criterion (DIC) was used to evaluate how well the model fit the data in comparison with another model in terms of estimated complexity (the smaller the DIC, the better the model fit).

A multilevel linear regression model using restricted maximum likelihood was fit to estimate the average relationships among SRH, regional social capital, and compositional variables. Individual and regional fixed effects were expressed by partial regression coefficients. Statistical analyses were conducted using PASW statistics ver. 18.0 and HLM ver. 6.02. [21].

We used hierarchical testing to assess the relationships among three aspects of regional social capital, compositional variables, and health outcome for the residents of 118 regions. In the first step, each regional variable adjusted for regional size and survey year was included, respectively, to assess whether contextual effects were statistically significant (models 1, 3, and 5). In the second step, both individual factors and each regional factor were included simultaneously to assess contextual effects after controlling for compositional variables, respectively (models 2, 4, and 6). A two-sided $p$ value $<0.05$ was considered to be statistically significant.

\section{Results}

The study variables are presented in Table 1 . The mean age \pm the standard deviation (SD) of the participants was $51.6 \pm 16.6$ years, and more than $60 \%$ of the participants were female.

The mean $( \pm$ SD) SRH score among the 11,702 participants was $2.52 \pm 1.15$. The mean $( \pm \mathrm{SD})$ percentage of regional social trust among 118 regions was $21.0 \pm 4.4 \%$ (range 12.0-35.0\%), mean neighborhood safety was $55.0 \pm 10.8 \%$ (range 33.0-80.0\%), and mean social participation was $39.3 \pm 6.8 \%(23.0-61.0 \%)$.

The results of the multilevel linear regression analysis for SRH are shown in Table 2. A null model consists of constant terms, with a regional random variance that accounts for the variation in SRH across regions. The regional variance $( \pm \mathrm{SD})$ in the null model for SRH was $0.01 \pm 0.10$, which was significant ( $p<0.001$; data not shown in table). This model showed a difference in SRH among regions.

Results of models 1-6 are shown in Table 2. In models 1 and 2, regional social trust was considered. In model 1, 
Table 1 Study variables ( $n=11,702$ respondents)

\begin{tabular}{|c|c|c|c|}
\hline Study variables & $n$ & $\%$ & $\begin{array}{l}\text { Mean }( \pm \text { SD }) \\
\text { of SRH }\end{array}$ \\
\hline \multicolumn{4}{|l|}{ Year } \\
\hline 2000 & 2,617 & 22.4 & $2.59 \pm 1.15$ \\
\hline 2001 & 2,421 & 20.7 & $2.57 \pm 1.15$ \\
\hline 2002 & 2,762 & 23.6 & $2.57 \pm 1.14$ \\
\hline 2005 & 1,900 & 16.2 & $2.43 \pm 1.18$ \\
\hline 2006 & 2,002 & 17.1 & $2.37 \pm 1.10$ \\
\hline \multicolumn{4}{|l|}{ Age (years) } \\
\hline $20-29$ & 1,392 & 11.9 & $2.17 \pm 1.1$ \\
\hline $30-39$ & 1,779 & 15.2 & $2.37 \pm 1.1$ \\
\hline $40-49$ & 1,929 & 16.5 & $2.49 \pm 1.05$ \\
\hline $50-59$ & 2,507 & 21.4 & $2.49 \pm 1.11$ \\
\hline $60-69$ & 2,216 & 18.9 & $2.63 \pm 1.18$ \\
\hline $70-79$ & 1,451 & 12.4 & $2.82 \pm 1.22$ \\
\hline $80-89$ & 428 & 3.7 & $2.94 \pm 1.29$ \\
\hline \multicolumn{4}{|l|}{ Sex } \\
\hline Male & 5,390 & 46.1 & $2.55 \pm 1.14$ \\
\hline Female & 6,312 & 63.9 & $2.49 \pm 1.16$ \\
\hline \multicolumn{4}{|l|}{ Marital status } \\
\hline Single & 1,757 & 15 & $2.52 \pm 1.13$ \\
\hline Married/cohabiting & 8,609 & 73.6 & $2.35 \pm 1.13$ \\
\hline Divorced/separated/widowed & 1,336 & 11.4 & $2.71 \pm 1.24$ \\
\hline \multicolumn{4}{|l|}{ Education } \\
\hline Primary (<12 years) & 1,053 & 9.0 & $2.92 \pm 1.28$ \\
\hline$\geq 12$ years & 6,990 & 59.7 & $2.55 \pm 1.15$ \\
\hline$\geq 14$ years & 1,328 & 11.3 & $2.42 \pm 1.12$ \\
\hline$\geq 16$ years & 2,331 & 19.9 & $2.30 \pm 1.05$ \\
\hline \multicolumn{4}{|l|}{ Employment status } \\
\hline Regular employee & 3,718 & 31.8 & $2.41 \pm 1.06$ \\
\hline Part-time worker & 1,314 & 11.2 & $2.38 \pm 1.09$ \\
\hline Temporary worker & 337 & 2.9 & $2.23 \pm 1.05$ \\
\hline Self-employed/family worker & 1,457 & 12.5 & $2.38 \pm 1.11$ \\
\hline Unemployed & 4,403 & 37.6 & $2.74 \pm 1.22$ \\
\hline Executive & 473 & 4.0 & $2.36 \pm 1.09$ \\
\hline \multicolumn{4}{|l|}{ Household income (million yen) } \\
\hline Lowest quartile $(<2.0)$ & 1,799 & 15.4 & $2.73 \pm 1.23$ \\
\hline 2nd quartile (2.0-2.9) & 1,805 & 15.4 & $2.51 \pm 1.15$ \\
\hline 3rd quartile (3.0-4.5) & 1,893 & 16.2 & $2.45 \pm 1.10$ \\
\hline Highest quartile ( $\geq 4.5$ ) & 2,117 & 18.1 & $2.38 \pm 1.06$ \\
\hline Missing income information & 4,088 & 34.9 & $2.53 \pm 1.16$ \\
\hline \multicolumn{4}{|l|}{ Self-rated health $(2.52 \pm 1.15)$} \\
\hline 1. Good & 2,830 & 24.2 & \\
\hline 2. & 2,846 & 24.3 & \\
\hline 3. & 3,702 & 31.6 & \\
\hline 4. & 1,776 & 15.2 & \\
\hline 5. Poor & 548 & 4.7 & \\
\hline \multicolumn{4}{|l|}{ Social trust } \\
\hline Yes & 2,526 & 21.6 & $2.29 \pm 1.14$ \\
\hline
\end{tabular}

Table 1 continued

\begin{tabular}{llll}
\hline Study variables & $n$ & $\%$ & $\begin{array}{l}\text { Mean }( \pm \text { SD) } \\
\text { of SRH }\end{array}$ \\
\hline No & 1,398 & 11.9 & $2.69 \pm 1.24$ \\
$\quad$ Depends & 7,778 & 66.5 & $2.56 \pm 1.12$ \\
Neighborhood safety & & & \\
$\quad$ Yes (reference) & 6,467 & 55.3 & $2.53 \pm 1.14$ \\
$\quad$ No & 5,235 & 44.7 & $2.51 \pm 1.16$ \\
Social participation & & & \\
$\quad$ Yes & 4,600 & 39.3 & $2.41 \pm 1.11$ \\
$\quad$ No (reference) & 7,102 & 60.7 & $2.59 \pm 1.17$ \\
Regional size & & & \\
$\quad$ Large & 2,252 & 19.2 & $2.51 \pm 1.14$ \\
Middle & 6,198 & 53.0 & $2.51 \pm 1.14$ \\
$\quad$ Small & 3,252 & 27.8 & $2.54 \pm 1.16$ \\
\hline SRH Self-rated & & & \\
\hline
\end{tabular}

SRH Self-rated health, SD standard deviation

regional social trust reached statistical significance $(p<0.001)$ and was negatively associated with poor SRH. In model 2, after adjusting for individual demographic factors and SES, regional social trust remained significant $(p<0.001)$, and health gradients were observed based on age, gender, and education. Poor SRH was significantly associated with older rather than younger age $(p<0.001)$ and with male gender $(p<0.001)$, suggesting that older people and males tended to report poor SRH. Poor SRH was also negatively associated with $\geq 16$ years of education, and a gradient was observed with respect to level of education. Moreover, poor SRH was also negatively associated with income level in the second quartile $(p<0.001)$, third quartile $(p<0.001)$, and highest quartile $(p<0.001)$. However, a clear gradient was not evident with regard to income level. Poor SRH was also negatively associated with employment status for executives $(p=0.011)$, parttime workers $(p=0.048)$, self-employed/family workers $(p<0.001)$, and unemployed participants $(p<0.001)$. Similar compositional effects with regard to income, education, and employment status were also observed in models 2,4 , and 6 .

The regional level of neighborhood safety was assessed in models 3 and 4 . In model 3, the association between a lack of regional neighborhood safety and poor SRH was statistically significant $(p=0.019)$. In model 4 , both contextual and compositional variables were included simultaneously to estimate the contextual effect on SRH after adjusting for individual and SES variables. In this model, neighborhood safety did not reach significance.

In models 5 and 6 , the association between SRH and the regional level of social participation was also assessed. In model 5, this association did not reach significance. 
Table 2 Results of multilevel regression analysis for self-rated health in the Japanese population: partial regression coefficients of individual and regional variables from the JGSS

\begin{tabular}{|c|c|c|c|c|c|c|c|c|c|}
\hline \multirow[t]{2}{*}{ Individual/ regional variables } & \multicolumn{3}{|l|}{ Model 1} & \multicolumn{3}{|l|}{ Model 2} & \multicolumn{3}{|l|}{ Model 3} \\
\hline & Coefficient & $\begin{array}{l}\text { Standard } \\
\text { error }\end{array}$ & $p$ & Coefficient & $\begin{array}{l}\text { Standard } \\
\text { error }\end{array}$ & $p$ & Coefficient & $\begin{array}{l}\text { Standard } \\
\text { error }\end{array}$ & $p$ \\
\hline \multicolumn{10}{|l|}{ Level $1(n=11702)$} \\
\hline Intercept & 2.827 & 0.089 & $<0.001$ & 2.513 & 0.099 & $<0.001$ & 2.726 & 0.092 & $<0.001$ \\
\hline \multicolumn{10}{|l|}{ Sex (ref. female) } \\
\hline Male & & & & 0.125 & 0.024 & $<0.001$ & & & \\
\hline Age & & & & 0.009 & 0.001 & $<0.001$ & & & \\
\hline \multicolumn{10}{|c|}{ Marital status (ref. married/cohabiting) } \\
\hline Single & & & & 0.026 & 0.034 & 0.444 & & & \\
\hline $\begin{array}{l}\text { Divorced/separated/ } \\
\text { widowed }\end{array}$ & & & & -0.022 & 0.036 & 0.560 & & & \\
\hline \multicolumn{10}{|l|}{ Education (ref. $\geq 12$ years) } \\
\hline Primarily (<12 years) & & & & 0.037 & 0.037 & 0.316 & & & \\
\hline$\geq 14$ years & & & & -0.052 & 0.034 & 0.134 & & & \\
\hline$\geq 16$ years & & & & -0.167 & 0.029 & $<0.001$ & & & \\
\hline \multicolumn{10}{|c|}{ Household income (ref. lowest quartile $<2.0$ ) } \\
\hline Missing income & & & & -0.101 & 0.032 & 0.002 & & & \\
\hline 2nd quartile (2.0-2.9) & & & & -0.189 & 0.038 & $<0.001$ & & & \\
\hline 3rd quartile (3.0-4.5) & & & & -0.138 & 0.038 & $<0.001$ & & & \\
\hline Highest quartile $\geq 4.5$ & & & & -0.206 & 0.042 & $<0.001$ & & & \\
\hline \multicolumn{10}{|c|}{ Employment status (ref. regular employee) } \\
\hline Executive & & & & -0.142 & 0.056 & 0.011 & & & \\
\hline Part-time worker & & & & -0.075 & 0.038 & 0.048 & & & \\
\hline Temporary worker & & & & -0.087 & 0.066 & 0.185 & & & \\
\hline $\begin{array}{l}\text { Self-employed/family } \\
\text { worker }\end{array}$ & & & & -0.158 & 0.036 & $<0.001$ & & & \\
\hline Unemployed & & & & 0.157 & 0.031 & $<0.001$ & & & \\
\hline \multicolumn{10}{|l|}{ Level $2(n=118)$} \\
\hline \multicolumn{10}{|l|}{ Regional size (ref. large) } \\
\hline Small & -0.003 & 0.029 & 0.913 & -0.044 & 0.028 & 0.115 & 0.008 & 0.031 & 0.799 \\
\hline \multicolumn{10}{|l|}{ Survey year (ref. 2000-2002) } \\
\hline $2005-2006$ & -0.178 & 0.024 & $<0.001$ & -0.183 & 0.023 & $<0.001$ & -0.145 & 0.028 & $<0.001$ \\
\hline \multicolumn{10}{|l|}{ Social capital } \\
\hline General trust $(\%)$ & -0.012 & 0.003 & $<0.001$ & -0.011 & 0.003 & $<0.001$ & & & \\
\hline Neighborhood safety (\%) & & & & & & & & & \\
\hline Social participation (\%) & & & & & & & -0.311 & 0.130 & 0.019 \\
\hline $\begin{array}{l}\text { Regional random } \\
\text { variance }( \pm \mathrm{SD})\end{array}$ & 0.0015 & 0.0382 & 0.195 & 0.0005 & 0.0233 & 0.315 & 0.0026 & 0.051 & 0.072 \\
\hline \multirow[t]{3}{*}{ Deviance } & \multicolumn{3}{|c|}{36379.5} & \multicolumn{3}{|c|}{35901.6} & \multicolumn{3}{|c|}{36389.64} \\
\hline & \multicolumn{3}{|l|}{ Model 4} & \multicolumn{3}{|l|}{ Model 5} & \multicolumn{3}{|l|}{ Model 6} \\
\hline & Coefficient & $\begin{array}{l}\text { Standard } \\
\text { error }\end{array}$ & $p$ & Coefficient & $\begin{array}{l}\text { Standard } \\
\text { error }\end{array}$ & $p$ & Coefficient & $\begin{array}{l}\text { Standard } \\
\text { error }\end{array}$ & $p$ \\
\hline \multicolumn{10}{|l|}{ Level $1(n=11702)$} \\
\hline Intercept & 2.304 & 0.105 & $<0.001$ & 2.642 & 0.106 & $<0.001$ & 2.265 & 0.114 & $<0.001$ \\
\hline \multicolumn{10}{|l|}{ Sex (ref. female) } \\
\hline Male & 0.124 & 0.024 & $<0.001$ & & & & 0.124 & 0.024 & $<0.001$ \\
\hline Age & 0.009 & 0.001 & $<0.001$ & & & & 0.009 & 0.001 & $<0.001$ \\
\hline
\end{tabular}


Table 2 continued

\begin{tabular}{|c|c|c|c|c|c|c|c|c|c|}
\hline & \multicolumn{3}{|l|}{ Model 4} & \multicolumn{3}{|l|}{ Model 5} & \multicolumn{3}{|l|}{ Model 6} \\
\hline & Coefficient & $\begin{array}{l}\text { Standard } \\
\text { error }\end{array}$ & $p$ & Coefficient & $\begin{array}{l}\text { Standard } \\
\text { error }\end{array}$ & $p$ & Coefficient & $\begin{array}{l}\text { Standard } \\
\text { error }\end{array}$ & $p$ \\
\hline Single & 0.025 & 0.034 & 0.473 & & & & 0.025 & 0.034 & 0.468 \\
\hline Divorced/separated/widowed & -0.019 & 0.036 & 0.594 & & & & -0.019 & 0.036 & 0.591 \\
\hline \multicolumn{10}{|l|}{ Education (ref. $\geq 12$ years) } \\
\hline Primarily (<12 years) & 0.032 & 0.037 & 0.383 & & & & 0.033 & 0.037 & 0.376 \\
\hline$\geq 14$ years & -0.052 & 0.035 & 0.132 & & & & -0.052 & 0.035 & 0.128 \\
\hline$\geq 16$ years & -0.169 & 0.029 & $<0.001$ & & & & -0.170 & 0.029 & $<0.001$ \\
\hline \multicolumn{10}{|c|}{ Household income (ref. lowest quartile $<2.0$ ) } \\
\hline Missing income & -0.101 & 0.032 & 0.002 & & & & -0.102 & 0.032 & 0.002 \\
\hline 2nd quartile (2.0-2.9) & -0.191 & 0.038 & $<0.001$ & & & & -0.191 & 0.038 & $<0.001$ \\
\hline 3rd quartile (3.0-4.5) & -0.140 & 0.038 & $<0.001$ & & & & -0.141 & 0.038 & $<0.001$ \\
\hline Highest quartile $\geq 4.5$ & -0.207 & 0.043 & $<0.001$ & & & & -0.209 & 0.043 & $<0.001$ \\
\hline \multicolumn{10}{|c|}{ Employment status (ref. regular employee) } \\
\hline Executive & -0.143 & 0.056 & 0.011 & & & & -0.142 & 0.056 & 0.011 \\
\hline Part-time worker & -0.075 & 0.038 & 0.050 & & & & -0.075 & 0.038 & 0.048 \\
\hline Temporary worker & -0.085 & 0.066 & 0.198 & & & & -0.085 & 0.066 & 0.196 \\
\hline Self-employed/Family worker & -0.158 & 0.036 & $<0.001$ & & & & -0.158 & 0.036 & $<0.001$ \\
\hline Unemployed & 0.158 & 0.031 & $<0.001$ & & & & 0.157 & 0.031 & $<0.001$ \\
\hline \multicolumn{10}{|l|}{ Level $2(n=118)$} \\
\hline \multicolumn{10}{|l|}{ Regional size (ref. large) } \\
\hline Small & -0.027 & 0.030 & 0.360 & 0.013 & 0.032 & 0.687 & -0.026 & 0.030 & 0.389 \\
\hline \multicolumn{10}{|l|}{ Survey year (ref. 2000-2002) } \\
\hline 2005-2006 & -0.171 & 0.029 & $<0.001$ & -0.171 & 0.026 & $<0.001$ & -0.179 & 0.025 & $<0.001$ \\
\hline \multicolumn{10}{|l|}{ Social capital } \\
\hline \multicolumn{10}{|l|}{ General trust $(\%)$} \\
\hline Neighborhood safety (\%) & -0.089 & 0.127 & 0.484 & & & & & & \\
\hline Social participation $(\%)$ & & & & -0.217 & 0.217 & 0.320 & -0.023 & 0.207 & 0.913 \\
\hline Regional random variance $( \pm \mathrm{SD})$ & 0.0022 & 0.0471 & 0.076 & 0.0034 & 0.0583 & 0.033 & 0.0023 & 0.0478 & 0.068 \\
\hline Deviance & & 35917.6 & & & 36393.1 & & & 35917 & \\
\hline
\end{tabular}

JGSS Japanese General Social Surveys

In model 5, regional social participation also failed to reach significance after adjusting for compositional factors.

Models 1-6 consistently indicated that regional size did not have a significant effect, whereas survey year was a significant factor, and the 2005-2006 survey period was negatively associated with poor SRH compared with the 2000-2002 period.

Deviation values were lowest in model 2, which therefore showed the best fit among models 1-6.

\section{Discussion}

Although a number of studies on social capital and health outcome have been conducted in Western societies, few such investigations have been conducted among the
Japanese population. Therefore, the question of whether regional social capital is linked to individual health in Japan is still unanswered. Several studies have been conducted on ecological design [22-24]; however, few multilevel data analyses have focused on the issue of whether there is a regional contextual effect for individual health among a Japanese population (see Table 3). Fujisawa et al. [25] found a contextual effect of social capital (perceived helpfulness, kindness, and greetings as a social-cohesion index) on health outcomes within small districts, and Ichida et al. [26] similarly found that high social trust was significantly associated with good SRH within small communities. Suzuki et al. [27] reported that company-level mistrust was associated with poor health, and Hamano et al. [28] observed that cognitive and structural aspects of social capital were associated with mental health within 


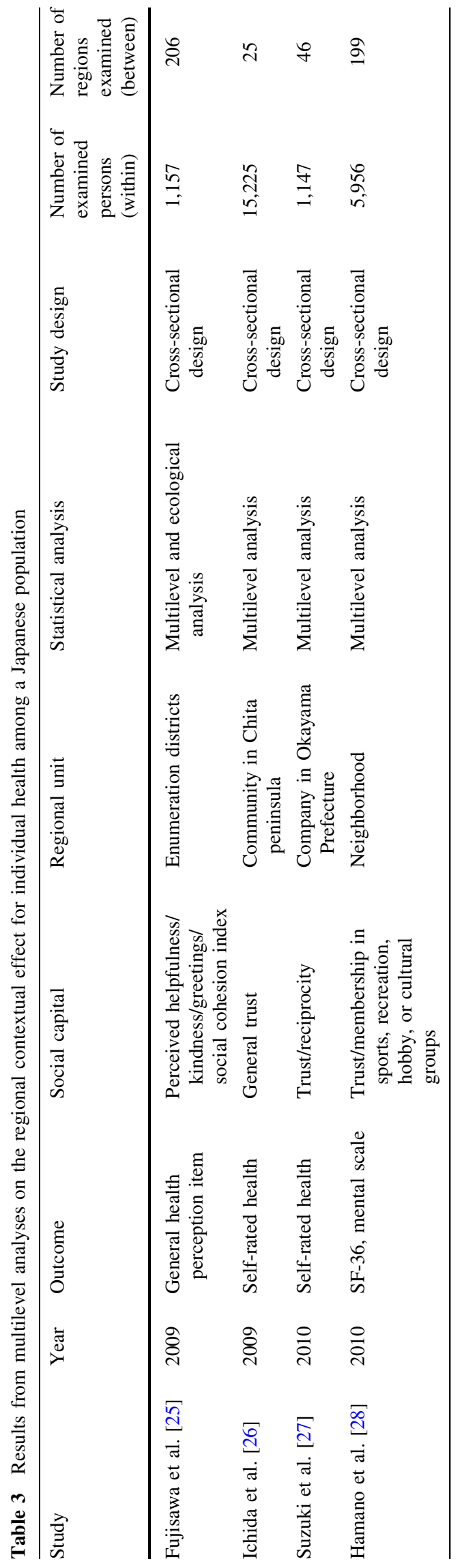

neighborhoods. In summary, these studies adopted a relatively small regional scale among the Japanese population and found significant contextual effects of social capital on health.

In our study, we have attempted to determine the relationship between three kinds of social capital and SRH after adjusting for compositional factors. The results provide new information based on JGSS data, which is a nationwide representative sample.

Null models with constant terms were the only ones that showed significant unexplained regional variance in SRH, suggesting that we should explore which factors explained these regional variances.

In general, there are two hypotheses for the path linking regional social capital with individual health. One points to a compositional effect, in which a resident's health is affected by individual resident characteristics; the other suggests a contextual effect, in which a resident's health is affected by regional characteristics. The multilevel analysis enabled us to control for the compositional and contextual effects and thereby determine the contribution of each to SRH.

There is an abundance of well-established evidence supporting the role of compositional factors in shaping health. Socioeconomic factors, such as education, income, and employment, are known to determine individual health outcomes [1]. We also observed this health gradient using the JGSS educational data. However, income level and employment status did not show a dose-response relationship: income level showed a dose-response relationship in univariate analysis, but this relationship disappeared in the multivariate analysis. In the multilevel analysis, people in the second income quartile reported better health than those in the third income quartile. The reason for these contradictory results might be attributed to a confounding factor. Further study will be needed to explore health gradients by individual socioeconomic status. These results indicate that we should test whether regional social capital remains significant after adjusting for these compositional factors.

In our study, we examined the cognitive and structural aspects of social capital simultaneously, focusing on social trust, which is one of the cognitive aspects of social capital. Social capital had a significant contextual effect on individual SRH in 118 regions. Moreover, model 2 was the best fit among the models assessed in our study.

In previous studies, numerous indicators were used as surrogate variables for social capital, although various social capital theories are not mutually exclusive [29]. For example, trust [30], reciprocity [27], neighborhood safety [31], sense of insecurity (a cognitive dimension) [32], voting in elections [33], social networks [34], and social participation (a structural dimension) [28] have all been considered to be elements of social capital. Moreover, social capital has been regarded as having vertical and horizontal dimensions: 
the vertical dimension includes factors such as civic trust and participation, and the horizontal dimension includes factors such as political trust and participation [3]. Various social capital dimensions may affect health outcomes differently. For example, De Silva [35] found that cognitive social capital is a better predictor of good health, whereas structural social capital is a better predictor of poor health. However, the validity and credibility of various socialcapital indicators have not been well established.

Nevertheless, social or generalized trust is widely regarded as a cognitive aspect of social capital [13, 30, 31] both domestically and overseas, and the single-item measurement of trust is widely accepted as a valid indicator of social capital [36]. For example, Kawachi [14] adopted aggregated social trust for studying regional social capital among 39 U.S. states and found a contextual effect on SRH.

Moreover, aggregated individual social capital considered at the regional level has been examined at various regional scales, including the country [37], state [13], parish [38], and neighborhood level [25, 26]. We found an association between regional social trust within 118 regions according to city size and prefecture. However, precisely which regional scale is appropriate for assessing the relationship between social trust and residents' health in the Japanese population remains unclear. There may be a difference between urban and rural areas [39], as city size was not significantly related to SRH in our study. Moreover, the response rates were unclear in our study, and there may have been a difference in response rates between urban and rural areas.

Several potential mechanisms that might account for the influence of regional social capital on SRH have been demonstrated. First, regional social capital might influence the health behaviors of community residents. Second, regional social capital might influence health by increasing access to local services and amenities. Third, regional social capital might influence the health of individuals, via psychosocial processes, by providing emotional support and promoting self-esteem, mutual respect, and reciprocal relationships [1].

The results of our study may imply a psychosocial process linking regional social capital and health outcomes. A population approach that strengthens trust for others might be an important and valid means for improving the health of Japanese community residents.

In summary, we have examined three kinds of social capital with both cognitive and structural dimensions and found that social trust was the most important factor influencing individual SRH. Our results were partially consistent with those of a number of other multilevel studies, which found significant protective effects of social trust for an area after adjusting for similar individual demographic and SES factors [25, 26, 38].
There are a number of limitations and strengths to this study. First, the cross-sectional nature of the data limited our ability to demonstrate causality. Therefore, the significant association between social trust and SRH might reflect reverse causation and might be the result of a social selection process. The robustness of the findings should be assessed with additional longitudinal data. We used a nationally representative sample with stratified random sampling; however, our overall response rate was not high, and the relatively large amount of missing data in response to the income inquiry may have increased the existing response bias. It is known that low response rates to questionnaires may result in the loss of poor and/or wealthy samples, leading to a misunderstanding of the extent of the relationship between social capital and health [40]. However, how existing systematic errors based on missing information with regard to income level might affect the results is not known. Moreover, those respondents with poor health and low social capital tended to refuse to participate in the study, and this selection bias may have affected the results. The variance in social capital at the regional level was relatively low. Nevertheless, few studies have examined the relationships between cognitive and structural dimensions of regional social capital and SRH among a Japanese population using a multilevel analysis and a nationwide sample. Therefore, the results of this study represent a baseline for future studies.

\section{Conclusion}

We found evidence that regional social trust was associated with good SRH after adjusting for possible confounding and compositional factors. Further study will be needed to clarify the pathway linking trust in others to health outcomes in the Japanese population.

Acknowledgments This study was supported by the Pfizer Health Research Foundation. The Japanese General Social Surveys (JGSS) were designed and conducted by the JGSS Research Center at Osaka University of Commerce (Joint Use/Research Center for Japanese General Social Surveys accredited by the Ministry of Education, Culture, Sports, Science and Technology) in collaboration with the Institute of Social Science at the University of Tokyo.

Conflict of interest The authors declare no competing interests.

\section{References}

1. Kawachi I, Berkman LF. Social cohesion, social capital, and health. In: Berkman LF, Kawachi I, editors. Social epidemiology. New York: Oxford University Press; 2000. p. 174-90.

2. Putnam R, Leonardi R, Nanatti R. Making demography work: civic traditions in modern Italy. Princeton: Princeton University Press; 1993. p. 167. 
3. Harpham T. The measurement of community social capital through surveys. In: Kawachi I, Subramanian SV, Kim D, editors. Social capital and health. New York: Springer; 2003. p. 51-62.

4. Kawachi I, Kennedy BP, Glass R. Social capital and self-rated health: a contextual analysis. Am J Public Health. 1999;89(8): 1187-93.

5. Wilkinson RG. Unhealthy societies: the afflictions of inequality. London: Routledge; 1996.

6. Jen $\mathrm{MH}$, Jones $\mathrm{K}$, Johnston R. Global variations in health: evaluating Wilkinson's income inequality hypothesis using the World Values Survey. Soc Sci Med. 2009;68:643-53.

7. Islam MK, Merlo J, Kawachi I, Lindstrom M, Gerdtham U. Social capital and health: does egalitarian egalitarianism matter? Int J Equity Health. 2006;5(3):1-28.

8. Marmott MG, Smith GD. Why are the Japanese living longer? Br Med J. 1989;299:1547-51.

9. Hawe P, Shiell A. Social capital and health promotion: a review. Soc Sci Med. 2000;51(6):871-85.

10. Sundquist K, Yang M. Linking social capital and self-rated health: a multilevel analysis of 11, 175 men and women in Sweden. Health Place. 2007;13(2):324-34.

11. Subramanian SV, Kawachi I, Kennedy BP. Does the state you live in make a difference? Multilevel analysis of self-rated health in the US. Soc Sci Med. 2001;53(1):9-19.

12. Dressler WM, Badger LW. Epidemiology of depressive symptoms in black communities. A comparative analysis. J Nerv Ment Dis. 1985;173(4):212-20.

13. Kawachi I, Kennedy BP, Lochner K, Prothrow-Stith D. Social capital, income inequality, and mortality. Am J Public Health. 1997;87(9):1491-8.

14. Kawachi I. Social capital and community effects on population and individual health. Ann N Y Acad Sci. 1999;896:120-30.

15. Idler EL, Angel RJ. Self-rated health and mortality in the NHANES-I Epidemiologic Follow-up Study. Am J Public Health. 1990;80(4):446-52.

16. Miilunpalo S, Vuori I, Oja P, Pasanen M, Urponen H. Self-rated health status as a health measure: the predictive value of selfreported health status on the use of physician services and on mortality in the working-age population. J Clin Epidemiol. 1997;50(5):517-28.

17. Mossey JM, Shapiro E. Self-rated health: a predictor of mortality among the elderly. Am J Public Health. 1982;72(8):800-8.

18. Idler EL, Benyamini Y. Self-rated health and mortality: a review of twenty-seven community studies. J Health Soc Behav. 1997; 38:21-37.

19. Atkinson AB, Rainwater L, Smeeding TM. Income distribution in OECD countries. Evidence from Luxemburg income study. Paris: Organization for Economic Cooperation and Development; 1995.

20. Goldstein H. Multilevel statistical models. London: Arnold; 2003.

21. Raudenbush SW, Bryk AS. Hierarchical linear models: applications and data analysis methods. 2nd ed. Newbury Park: Sage; 2004.

22. Inaba Y. Policy implications of social capital: based on the Cabinet Office's panel data (in Japanese with English Abstract). J Econ Policy. 2007;58:31-34.
23. Fujisawa Y, Hamano T, Koyabu A. Chikutanino social capital ga shukanteki kennkoukanni oyobosu eikyo (in Japanese with English abstract). Kouseino Shihyo. 2007;54(2):18-23.

24. Fujisawa Y, Hamano T, Nam EW, Koyabu A, Edirippulige S. Preliminary study of the relationship between social capital and health status (in Japanese with English abstract). Niigata J Health Welf. 2005;4(2):82-9.

25. Fujisawa Y, Hamano T, Kakegawa S. Social capital and perceived health in Japan: an ecological and multilevel analysis. Soc Sci Med. 2009;69(4):500-5.

26. Ichida Y, Kondo K, Hirai H, Hanibuchi T, Yoshikawa G, Murata C. Social capital, income inequality and self-rated health in Chita peninsula, Japan: a multilevel analysis of older people in 25 communities. Soc Sci Med. 2009;69(4):489-99.

27. Suzuki E, Takao S, Subramanian SV, Kimatsu H, Doi H, Kawachi I. Does low workplace social capital have detrimental effect on workers' health? Soc Sci Med. 2010;70:1367-72.

28. Hamano T, Fujisawa Y, Ishida Y, Subramanian SV, Kawachi I, Shiwaku K. Social capital and mental health in Japan: a multilevel analysis. PLoS One. 2010;5(10):1-6.

29. Kawachi I. Commentary: social capital and health: making the connections one step at a time. Int J Epidemiol. 2006;35:989-93.

30. Fujisawa T, Kawachi I. A prospective study of individual-level social capital and major depression in the United States. J Epidemiol Community Health. 2008;62:627-33.

31. Poortinga W, Dunstan FD, Fone DL. Neighbourhood deprivation and self-rated health: the role of perceptions of the neighbourhood and of housing problems. Health Place. 2008;14:562-75.

32. Lindström M, Merlo J, Ostergern PO. Social capital and sense of insecurity in the neighborhood: a population-based multilevel analysis in Malmö, Sweden. Soc Sci Med. 2003;56:1111-20.

33. Sundquist K, Yang M. Linking social capital and self-rated health: a multilevel analysis of 11, 175 men and women in Sweden. Health Place. 2007;13:324-34.

34. Lakon CM, Godette DC, Hipp, JR. Network-based approaches for measuring social capital. In: Kawachi I, Subramanian SV, Kim D, editors. Social capital and Health. New York: Springer; 2008. pp. 63-81.

35. De Silva MJ, McKenzie K, Harpham T, Hutty S. Social capital and mental illness: a systematic review. J Epidemiol Community Health. 2005;59:619-27.

36. Helliwell JF, Putman RD. The social context of well-being. Philos Trans R Soc Lond B Bio Sci. 2004;359:1435-46.

37. Uslaner E. The moral foundations of trust. New York: Cambridge University Press; 2002.

38. Engström K, Mattsson F, Järleborg A, Hallqvist J. Contextual social capital as a risk factor for poor self-rated health: a multilevel analysis. Soc Sci Med. 2008;66(11):2268-80.

39. Yip W, Subramanian SV, Mitchell AD, Lee DT, Wang J. Does social capital enhance health and well-being? Evidence from rural China. Soc Sci Med. 2007;64:35-49.

40. Mclsaac SJ, Wilkinson RG. Income distribution and cause-specific mortality. Eur J Public Health. 1997;7(1):45-53. 